\title{
Dose Dependent Course of Hyperprolactinemic and Normoprolactinemic Galactorrhea Induced by Venlafaxine
}

\author{
Mehmet Akif Camkurt ${ }^{1}$, Gizem Gülpamuk ${ }^{2}$, Ebru Fındiklı ${ }^{3}$, Rengin Elve ${ }^{4}$ \\ Departments of ${ }^{1}$ Psychiatry and ${ }^{4}$ Internal Medicine, Afşin State Hospital, Afşin, ${ }^{2}$ Department of Psychiatry, Selçuk University School of Medicine, \\ Selçuk, ${ }^{3}$ Department of Psychiatry, Kahramanmaraş Sütçü İmam University, Kahramanmaraş, Turkey
}

\begin{abstract}
Venlafaxine is a serotonergic and noradrenergic reuptake inhibitor which is used for the treatment of depression. We report a case of galactorrhea in a patient with major depressive disorder after starting treatment with venlafaxine. In particular, we discuss the course of hyper and normoprolactinemic galactorrhea. We managed this side effect initially by dose reduction and further by switching to essitalopram. Physicians should be aware of endocrinologic side effects such as galactorrhea during the serotonin and noradrenaline reuptake inhibitor treatment.
\end{abstract}

KEY WORDS: Venlafaxine hydrochloride; Galactorrhea; Prolactin; Depression; Therapeutics; Management.

\section{INTRODUCTION}

Venlafaxine, a serotonin and noradrenaline reuptake inhibitor (SNRI), is a major drug for the treatment of major depressive disorder. However, it often causes gastrointestinal side effects such as nausea, vomiting and diarrhea. Less frequently, venlafaxine is responsible for adverse sexual side effects as well. ${ }^{1,2)}$

Although galactorrhea is frequently reported with antipsychotic drugs - which block the dopaminergic receptors and accompany elevated prolactin levels - there are several reports of galactorrhea with different classes of antidepressants. ${ }^{3)}$ The first report of galactorrhea was with clomipramine. Afterwards, there have been reports of galactorrhea with mostly serotonergic antidepressants, but rarely with SNRIs. ${ }^{4-7)}$ Another interesting feature of galactorrhea as a side effect of antidepressants is normoprolactinemic galactorrhea. Furthermore, galactorrhea may be dose-dependent in some cases. ${ }^{8)}$ In this case, we report a dose-dependent galactorrhea case involving both increased and normal prolactin levels, and the management of this condition in a depressed patient who used venlafaxine in a dose range of 225 to $75 \mathrm{mg} /$ day.

\footnotetext{
Received: February 22, 2016 / Revised: March 19, 2016

Accepted: April 3, 2016

Address for correspondence: Mehmet Akif Camkurt, MD Department of Psychiatry, Afşin State Hospital, Yeşilyurt Mah. Kemal Ertekin Cad., Afşin 46500, Turkey

Tel: +90-506-4404400, Fax: +90-344-5112966

E-mail:dr.akif@gmail.com
}

CASE

A 34-year-old female patient was admitted to our clinic with complaints of anhedonia, decreased appetite, loss of sexual desire, irritability and passive suicidal thoughts. These complaints had lasted about two months. The patient was considered to have major depressive disorder, so we initiated venlafaxine, $75 \mathrm{mg}$ /day. Six months after this initiation, we increased the dose of venlafaxine to $150 \mathrm{mg}$, because the patient was not admitted to the clinic regularly.

Three months later (the ninth month of treatment), we increased the venlafaxine dose to $225 \mathrm{mg}$ /day. The patient started to experience galactorrhea while she was taking $150 \mathrm{mg} /$ day, but she did not inform us about this side effect during our examination, so we increased the dose of venlafaxine. Ten days after taking venlafaxine at a dose of $225 \mathrm{mg} /$ day, the patient was admitted to our clinic again for galactorrhea that was so severe she could not endure it anymore. Brain magnetic resonance imaging was performed for her pituitary tumor, but the result was normal. We checked her hormone levels: FSH, LH, T3, T4 and TSH were within the normal range; however, her prolactin level was $156 \mathrm{ng} / \mathrm{ml}$. We considered the galactorrhea and the increased prolactin levels were a result of venlafaxine the patient had been taking. Consequently, we decreased the venlafaxine dose to $150 \mathrm{mg} /$ day.

One month later, although her prolactin level had de-

(a) This is an Open-Access article distributed under the terms of the Creative Commons Attribution Non-Commercial License (http://creativecommons.org/licenses/by-nc/4.0) which permits unrestricted non-commercial use, distribution, and reproduction in any medium, provided the original work is properly cited. 
creased to $9 \mathrm{ng} / \mathrm{ml}$, the galactorrhea persisted. So we decreased the venlafaxine dose to $75 \mathrm{mg} /$ day. At the patient's next visit, she stated that while she was taking $75 \mathrm{mg} /$ day, the galactorrhea symptoms had been significantly relieved, but she felt worse, so she started to take 150 $\mathrm{mg}$ /day again, which once more caused a severe case of galactorrhea. We decreased the dose of venlafaxine to 75 $\mathrm{mg} /$ day; afterwards, we switched the patient to escitalopram $10 \mathrm{mg} /$ day, and lorazepam $2 \mathrm{mg} /$ day. One month later, we increased the escitalopram dose to $20 \mathrm{mg} /$ day, and over the course of the following four weeks, we tapered the lorazepam dose. With a treatment of escitalopram 20 $\mathrm{mg} /$ day, the patient has reported that she is feeling very well; she was experiencing only minimal galactorrhea, but she chose to continue with escitalopram.

\section{DISCUSSION}

As far as we know, there is a limited number of case reports in literature involving galactorrhea with a measurement of increased prolactin levels developed under venlafaxine treatment.

Venlafaxine-induced galactorrhea, as seen in our case, was defined by Sternbach ${ }^{8)}$ in 2003 . He presented a 38 year-old-woman treated for depression and a binge eating disorder with a dosage of venlafaxine, $225 \mathrm{mg} /$ day. Six weeks after initiation of the treatment with venlafaxine (225 mg/day), buspirone $45 \mathrm{mg}$ was added to the treatment. While she was on this treatment for one week, she began to experience galactorrhea; her prolactin level was $32 \mu \mathrm{g} / \mathrm{L}$ (expected to be lower than $18 \mu \mathrm{g} / \mathrm{L}$ ). Despite a withdrawal of buspirone, her galactorrhea persisted at first, then stopped after the venlafaxine was withdrawn as well. Although venlafaxine $75 \mathrm{mg} /$ day was reapplied, the galactorrhea recurred. Meanwhile her prolactin level was $10 \mu \mathrm{g} / \mathrm{L}$.

Moreover, some of the clinicians managed hyperprolactinemia symptoms by reducing the dose of venlafaxine or stopping it. ${ }^{8-11)}$ When we decreased the dose of venlafaxine from 225 to $150 \mathrm{mg} /$ day, her prolactin level decreased from 156 to $9 \mathrm{ng} / \mathrm{ml}$, and interestingly enough, her galactorrhea continued, as in the cases of Sternbach, ${ }^{8)}$ Ashton and Longdon. ${ }^{10}$

The interesting points of our case are the facts that galactorrhea was both hyperprolactinemic and normoprolactinemic, and that the severity of the galactorrhea was clearly dose-related. At the beginning, we preferred to decrease the dose of venlafaxine in order to manage this side effect. Although the galactorrhea symptoms improved significantly after reducing the dose of venlafaxine to 75 $\mathrm{mg} /$ day, the patient's depressive symptoms occurred again, so we planned to switch to escitalopram. During the escitalopram treatment, she was still experiencing galactorrhea, but it was at a more tolerable level than during the venlafaxine treatment.

The most important observations of our report are as following; in our case, that venlafaxine was the only medication related to galactorrhea, because when the patient began taking a dosage of $150 \mathrm{mg} /$ day again, there were clear signs of an association existing between galactorrhea and venlafaxine. As stated previously, the more the venlafaxine dose is increased, the more the serotonergic transmission grows stronger. Also, the noradrenergic effects of venlafaxine start with doses of $225 \mathrm{mg}$ /day. Probable mechanisms related to both normoprolactinemic and hyperprolactinemic galactorrhea are serotonergic and noradrenergic pathways. ${ }^{6}$

Venlafaxine and its active metabolite (O-desmethylvenlafaxine) are SNRIs that weakly inhibit dopamine reuptake in high doses. ${ }^{6}$ It is not clear by which mechanism serotonergic agents increase prolactin levels or cause galactorrhea, but there are two pathways suggested to be related to these side effects. ${ }^{12)}$ Primarily, serotonin can directly stimulate 5-hydroxytryptamine (5-HT) receptors in the paraventricular nucleus of the hypothalamus, and this stimulation induces the release of vasoactive intestinal peptide (VIP) and oxytocin (OT). Both VIP and OT are known as prolactin-releasing factors. Another mechanism of serotonin-induced prolactin release is the indirect inhibition of dopaminergic neurons of the tuberoinfundibular pathway through 5-HT. Eventually, both mechanisms explain serotonin's potential effects on the neuroendocrine system. ${ }^{13)}$

In light of the observations from this case, we propose that venlafaxine is associated with both hyperprolactinemic and normoprolactinemic galactorrhea. Moreover, this report can help medical professionals to more effectively identify the association between venlafaxine and galactorrhea. Possible options for management of galactorrhea include dose reduction or switching to another antidepressant. Clinicians should be aware of that serotonergic or noradrenergic drugs may be associated with endocrinological side effects, especially galactorrhea.

\section{REFERENCES}

1. Camkurt MA. Spontaneous ejaculation; caused by venlafaxine, reverted by mirtazapine. Eur Res J 2015;1:157-159.

2. Tang M, Osser DN. The psychopharmacology algorithm 
project at the harvard south shore program: 2012 update on psychotic depression. J Mood Disord 2012;2:168-179.

3. Albayrak Y, Ünsal C, Beyazyüz M, Kuloğlu M. Comparison of short term effects of risperidone and paliperidone on serum prolactin levels in female patients. J Mood Disord 2014;4:7-13.

4. Anand VS. Clomipramine-induced galactorrhoea and amenorrhoea. Br J Psychiatry 1985;147:87-88.

5. Camkurt MA, Şimşek N. Sertralin induced normoprolactinemic galactorrhea. J Neurobehav Sci 2015;2:34-35.

6. Tesia SS, Tesia P, Gowda MR, Preeti S. Escitalopram induced euprolactinemic galactorrhoea. J Mood Disord 2012;2:15-16.

7. Chatterjee SS, Mitra S, Mallik N. Emerging hyperprolactinemic galactorrhea in obsessive compulsive disorder with a stable dose of fluoxetine. Clin Psychopharmacol Neurosci 2015; 13:316-318.

8. Sternbach H. Venlafaxine-induced galactorrhea. J Clin
Psychopharmacol 2003;23:109-110.

9. Yang MS, Cheng WJ, Huang MC. Dose-related hyperprolactinemia induced by venlafaxine. Prog Neuropsychopharmacol Biol Psychiatry 2009;33:733-734.

10. Ashton AK, Longdon MC. Hyperprolactinemia and galactorrhea induced by serotonin and norepinephrine reuptake inhibiting antidepressants. Am J Psychiatry 2007; 164:1121-1122.

11. Wichman CL, Cunningham JL. A case of venlafaxineinduced galactorrhea? J Clin Psychopharmacol 2008;28: 580-581.

12. Muth EA, Haskins JT, Moyer JA, Husbands GE, Nielsen ST, Sigg EB. Antidepressant biochemical profile of the novel bicyclic compound $W y-45,030$, an ethyl cyclohexanol derivative. Biochem Pharmacol 1986;35:4493-4497.

13. Emiliano AB, Fudge JL. From galactorrhea to osteopenia: rethinking serotonin-prolactin interactions. Neuropsychopharmacology 2004;29:833-846. 